\title{
Alkaloids Isolated from Ephedra Alata: Characterization and Protective Effects Against Cisplatin-Induced Liver and Kidney Injuries in Mice
}

\author{
Fairouz Sioud ${ }^{1 *}$, Sven Mangelinckx ${ }^{3}$, Aida Lahmer ${ }^{1,2}$, Eli Bonneure ${ }^{3}$, Fadwa Chaabene ${ }^{1}$ and Leila \\ chekir Ghedira ${ }^{1,2}$ \\ ${ }^{1}$ Unit of Bioactive and Natural Substances and Biotechnology UR17ES49, Faculty of dental medicine, University of Monastir, \\ Tunisia \\ ${ }^{2}$ Laboratory of pharmacognosy, Faculty of pharmacy, University of Monastir, Tunisia \\ ${ }^{3}$ SynBioC, Department of Green Chemistry and Technology, Faculty of Bioscience Engineering, Ghent University, Belgium
}

*Corresponding author: Fairouz Sioud, Laboratory of Cellular and Molecular Biology, Faculty of Dental Medicine, University of

Monastir, Rue Avicenne, Tunisia

\section{ARTICLE INFO}

Received: 峰 June 05, 2021

Published: 彗 June 14, 2021

Citation: Fairouz Sioud, Sven Mangelinckx, Aida Lahmer, Eli Bonneure, Fadwa Chaabene, Leila chekir Ghedira. Alkaloids Isolated from Ephedra Alata: Characterization and Protective Effects Against Cisplatin-Induced Liver and Kidney Injuries in Mice. Biomed J Sci \& Tech Res 36(3)2021. BJSTR. MS.ID.005861.

Keywords: Ephedra Alata; Alkaloids; Oxidative Stress; DNA Damage; Cisplatin Nephrotoxicity

\section{ABSTRACT}

Cisplatin (CP) is one of the most efficacious chemotherapeutic antitumor drugs. Oxidative stress has been proven to be involved in CP-induced toxicity. The aim of this study was designed to assess the protective effects of Ephedra alata alkaloids extract (AE) on liver and kidney injuries induced by CP. The $1 \mathrm{H}-\mathrm{RMN}$ analysis of AE extract detected the presence of ephedrine, pseudoephedrine, methylephedrine and methylpseudoephedrine. To evaluate the effect of $\mathrm{AE}$ extract on CP-toxicity, the mice were administrated with $150 \mathrm{mg} / \mathrm{kg}$ of AE for 7 days, and the liver and kidney injury models were established by single intraperitoneal injection of CP $(20 \mathrm{mg} / \mathrm{kg})$ on the fourth day. Compared with the model group, the activities of aspartate aminotransferase, alanine aminotransferase and the content of creatinine in serum all decreased in mice treated with $\mathrm{AE}$ extract. Meanwhile, the activities of superoxide dismutase, catalase increased, and the content of malondialdehyde and DNA damage decreased. In addition, the histopathologic aspects showed that the pathological changes of liver and kidney were found in the model group reduced after treatment with $\mathrm{AE}$. Therefore, $\mathrm{AE}$ could reduce the damage of liver and kidney caused by CP by reducing the level of oxidative stress, and improving the antioxidant, capacity of the body.

Abbreviations: SOD: Superoxide Dismutase; CAT: Catalase; MDA: Malondialdehyde; ROS: Reactive; Oxygen Species; DPPH: 2,2-Diphenyl-1-Picrylhydrazyl; AST: Aspartate Transaminase; ALT: Alanine Transaminase; CR: Creatinine; EDTA: Ethylenediaminetetraacetic Acid; $\mathrm{H}_{2} \mathrm{O}_{2}$ : Hydrogen Peroxide; TBARS: Thiobarbituric Acid Reactive Substances; TBA: Thiobarbituric Acid; TCA: Trichloroacetic Acid; EP: Ephedrine; PE: Pseudoephedrine; MPE: Methylpseudoephedrine; MEP: Methylephedrine; $\mathrm{H}_{2} \mathrm{SO}_{4}$ : Sulfuric Acid; KOH: Potassium Hydroxide; Nacl: Sodium Chloride; Cdcl3: Deuterated Chloroform; I.P: Intraperitoneal Injection.

\section{Introduction}

Cisplatin (CP), chemically known as cisdiamminedichloroplatinum II, is a widely used chemotherapeutic agent for different solid cancers such as testicular, ovarian, bladder, head and neck, endo metrial, cervical, and non-small cell lung carcinoma [1-5]. However, its clinic application is limited due to its serious side effects of neurotoxicity, ototoxicity, nausea and notably nephrotoxicity and liver dysfunction [6]. Studies investigating the link between CP 
dose and toxic side effects have principally suggested a correlation between CP cumulative dose and observed side effects. This can be significantly prominent for the liver and biological process system [7-9]. The uncontrolled reactive oxygen species (ROS) generation and the decrease in antioxidant capacity caused by CP further trigger apoptosis, DNA damage and inflammation in renal and hepatic tissues [10]. To prevent or limit cellular damage induced by oxidative stress, cells eliminate ROS by using endogenous enzymatic and non-enzymatic antioxidants. However, our endogenous antioxidant defense systems are incomplete without exogenous originating reducing compounds that we get from the diet such as vitamin $\mathrm{C}$, vitamin $\mathrm{E}$, carotenoids and polyphenols, playing an essential role in many antioxidant mechanisms in living organisms. Recently, research has targeted on the development of antioxidants and anti-inflammatory drugs extracted from medicinal plants to manage CP-induced renal injury [11].

Ephedra is one of the oldest drugs, having been used by the Chinese for at least 5000 years [12]. The in vitro and in vivo pharmacological studies on the crude extracts, fractions and few isolated compounds of Ephedra species showed anti-inflammatory, anticancer, antibacterial, antioxidant, hepatoprotective, anti-obesity, antiviral and diuretic activities [13]. The chemical compounds isolated from Ephedra species include alkaloids, amino acids and derivatives, volatiles, tannins, polysaccharides and phenolic compounds. Alkaloids are the main components with biological relevance of this genus such as ephedrine, pseudoephedrine, norephedrine, norpseudoephedrine, methylephedrine and methylpseudoephedrine. Furthermore, the E-type alkaloids, ephedroxane, and macrocyclic spermidines referred to as ephedradine A-D, have been found in some Eurasian Ephedra species [14]. Ephedrine/pseudoephedrine have long been used as drugs. As early as 1924, Chen and Schmidt published the first pharmacological study on ephedrine [15], and since then, ephedrine and its epimer pseudoephedrine have been widely investigated due to their sympathomimetic effects. These alkaloids are used clinically in treatments for diseases of the respiratory system such as colds, influenza and rhinitis, or as weight loss supplements [16]. Recently, several researchers started to look for other therapeutic aspects of Ephedra alkaloids such as the performance benefit [17], anticancer activity and the protective effect of ephedrine/pseudoephedrine on the liver injury mode [1820]. To date, no study has yet evaluated in vivo protective effects of Ephedra alata alkaloids on CP toxicity.

\section{Materials and Methods}

\section{Collection of Plant Material}

Ephedra alata was collected from the Sahara Desert of Tataouine, a region situated in the southeast of Tunisia, in February
2017. A voucher specimen has been kept in our laboratory for future reference. The aerial part of the plant material was shade dried, powdered and stored in a tightly closed container for further use.

\section{Preparation of Alkaloids Extract}

The alkaloids were extracted according to the method of Cui et al. [21]. Briefly, $200 \mathrm{mg}$ of Ephedra alata powder and $8 \mathrm{~mL}$ of sulfuric acid $(0.5 \mathrm{M})$ were shaken and sonicated for $1 \mathrm{~h}$ and then centrifuged for $20 \mathrm{~min}$ at $3000 \mathrm{rpm}$. The extraction of alkaloids from the supernatant was carried out with $5 \mathrm{~mL}$ of diethyl ether following addition of $1.4 \mathrm{~mL}$ of potassium hydroxide solution (5 M) and $2.4 \mathrm{~g}$ of sodium chloride. The mixture was shaken for 15 $\mathrm{min}$ and then centrifuged for $20 \mathrm{~min}$ at $3000 \mathrm{rpm}$. Extraction with diethyl ether was repeated twice. The combined diethyl ether layers were evaporated after addition of internal standard. The yield of the alkaloids extract (AE) was $1.2 \%$. Dried sample was dissolved in $1 \mathrm{~mL}$ of $\mathrm{CDCl}_{3}$ and used for ${ }^{1} \mathrm{H}$ NMR measurement.

\section{Proton Nuclear Magnetic Resonance Conditions}

To analyse the ephedrine alkaloids in $\mathrm{AE}$, we used a ${ }^{1} \mathrm{H}$ NMR method, which has proven to be optimal for detecting and/or quantifying ephedrine alkaloids of plant extracts. The ${ }^{1} \mathrm{H}$ NMR analysis was performed according to the method of Kim et al. [23]. A dried sample was dissolved in $1 \mathrm{~mL}$ of CDCl3 with $200 \mu \mathrm{g}$ of anthracene added as internal standard. $1 \mathrm{H}$ NMR spectra were recorded using a Bruker Avance-III $400 \mathrm{MHz}$ NMR spectrometer with the following parameters: 128 scans, $0.17 \mathrm{~Hz} /$ point, pulse width (PW) $7.08 \mu$ s and relaxation delay (RD) 1.0 s. FIDs were Fourier transformed with LB $0.30 \mathrm{~Hz}, \mathrm{~GB} 0 \mathrm{~Hz}$ and PC 1.0. The peak area was used for quantitative analysis and each signal was manually integrated. The amount of each alkaloid was calculated by the relative ratio of the intensity of the $\mathrm{H}-1$ signal of the alkaloid to the known amount of internal standard.

\section{2,2-Diphenyl-1-Picrylhydrazyl Assay}

The antioxidant activity of the extract was determined using the free radical 2,2-diphenyl-1-picrylhydrazyl (DPPH) assay, as described earlier with some modifications [24]. Briefly, $200 \mu \mathrm{L}$ of AE $(4-300 \mu \mathrm{g} / \mathrm{mL})$ were mixed with $3.8 \mathrm{~mL}$ DPPH solution and incubated in the dark at room temperature for $1 \mathrm{~h}$. The changes in optical density (OD) of the samples were measured at $515 \mathrm{~nm}$ with methanol as blank. The absorbance of the mixture was then measured at $517 \mathrm{~nm}$. Trolox was used as a positive control. The ability of the sample to scavenge DPPH radicals was calculated using the following formula:

$$
\text { DPPH scavengig effect }(\%)=\frac{\text { Control OD }- \text { Sample OD }}{\text { Control OD }} * 100
$$




\section{Experimental Animals}

Specific pathogen-free Balb/c mice (6-8-wk-old, male, $25 \mathrm{~g}$ ) were purchased from the Pasteur Institute (Tunis, Tunisia). All mice were housed under standard conditions of temperature $\left(22-28^{\circ} \mathrm{C}\right)$, humidity (30-70\%) and light (12/12 h light/dark) in an accredited pathogen-free facility. All animals were provided ad libitum access to standard rodent chow and filtered water. Directives regulating the welfare of experimental animals, and experiments were approved by the Life Sciences and Health Research Ethics Committee (cer-svs) of the Institute of Biotechnology (University of Monastir, Tunisia; ethical approval no. 2019/02/I/CER-SVS/ISBM; 9 January 2019.

\section{Acute Toxicity}

Mice were randomly divided into groups of 6 animals and treated by i.p. injection: AE was dissolved in PBS. The control group was treated by Intraperitoneal injection (i.p) saline solution (DMSO, 0.5\%). Mice were treated with different doses of extracts $(150,250,350,500$ and $800 \mathrm{mg} / \mathrm{kg})$. The number of dead animals was followed every day for one week after treatment.

\section{Experimental Design}

The mice were fed adaptively for 7 days and divided into four groups of six animals each and treated as follows:

a) Group 1 (Control) were administered saline solution (DMSO $0.5 \%$, randomly $2 \mathrm{ml} / \mathrm{kg}$, i.p.) daily for seven consecutive days, without any drug treatment.

b) Group 2 (AE) were administered i.p. $150 \mathrm{mg} / \mathrm{kg}$ of AE daily for seven consecutive days.

c) Group 3 (CP) were administered (DMSO 0.5\%, $2 \mathrm{ml} / \mathrm{kg}$, i.p.) daily for seven days. On the 4 th day, a single dose of CP (20 mg/ kg, i.p.) was given.

d) Group $4(\mathrm{AE}+\mathrm{CP})$ were administered i.p. $150 \mathrm{mg} / \mathrm{kg}$ of $\mathrm{AE}$ daily for seven days. On the 4 th day, a single dose of CP (20 $\mathrm{mg} / \mathrm{kg}$, i.p.) was given.

\section{Change in Bodyweight and Organ Coefficient}

The bodyweight of each animal was recorded before treatment and at the end of the experiment. Percentage change in bodyweight of mice was calculated. After mice were sacrificed, kidneys, livers and spleens were quickly excised from the animals and then the organ coefficient was determined.

\section{Sample Collection and Tissue Preparations}

Trunk blood samples were collected from the sacrificed animals and placed immediately on ice. Heparin was used as an anticoagulant and plasma samples were obtained by centrifugation at $1500 \mathrm{rpm}$ for $20 \mathrm{~min}$ and stored at $-60{ }^{\circ} \mathrm{C}$ until measurements. Stored plasma samples were analyzed for biochemical parameters.
The liver and kidney of mice were homogenized in the presence of $10 \mathrm{mM}$ Tris-HCl (pH 7.4) and centrifuged at 12,000 rpm for $30 \mathrm{~min}$ at $4{ }^{\circ} \mathrm{C}$. The supernatant was collected, aliquoted and stored at -80 ${ }^{\circ} \mathrm{C}$ until use. The total protein content was determined according to Bio-Rad protein assay [25] using bovine serum albumin as standard.

\section{Determination of Liver and Kidney Function Indexes}

Aspartate transaminase (AST) and alanine transaminase (ALT), Creatinine (CR) activities in plasma were determined with clinical chemistry analyser COBAS Cx72.

\section{Evaluation of Lipid Peroxidation Status}

Lipid peroxidation was determined using the thiobarbituric acid reactive substances (TBARS) assay [26]. Kidney and liver extracts $(50 \mu \mathrm{L})$ were mixed with trichloroacetic acid (1 ml, 20\%) and thiobarbituric acid $(1 \mathrm{ml}, 0.67 \%)$ and incubated at $95{ }^{\circ} \mathrm{C}$ for 2 hours. The reaction was stopped by immediate cooling in ice and then the samples were centrifuged at $860 \mathrm{~g}$ for $10 \mathrm{~min}$ at $4{ }^{\circ} \mathrm{C}$. The reaction between TBA and the lipids produced by oxidative degradation generate red complexes that absorb at $530 \mathrm{~nm}$ as measured using a microplate reader. The concentration of MDA (micromoles per milligram proteins) was obtained by extrapolating absorbance values to concentrations of a standard curve of MDA.

\section{Determination of Superoxide Dismutase Activity}

The superoxide dismutase (SOD) activity was evaluated by the inhibition of Nitro Blue Tetrazolium (NBT) reduction assay [26]. Kidney and liver extracts $(50 \mu \mathrm{l})$ were mixed with NBT $(2 \mathrm{mM})$, methionine $(10 \mathrm{mM})$, riboflavin $(2.4 \mathrm{mM})$ and EDTA $(0.1 \mathrm{mM})$. The reaction was carried out for 15 min illuminated with a UV fluorescent lamp. The absorbance was then measured at 560 $\mathrm{nm}$. An enzymatic unit was determined as the amount of cytosol required to inhibit $50 \%$ of the reaction without enzyme.

\section{Determination of Catalase Activity}

Determination of catalase activity was performed according to the method of Clairbone, 1985 [27]. The reaction mixture consisted of $20 \mu \mathrm{l}$ of kidney or liver extracts, phosphate buffer and hydrogen peroxide $(0.5 \mathrm{M})$. The reaction was measured at $240 \mathrm{~nm}$ using quartz cuvette. One unit of catalase activity was defined as the amount of enzyme required to decompose $1 \mu \mathrm{mol}$ of hydrogen peroxide.

\section{Histopathology}

For histological studies, the kidneys were collected from all the groups and were fixed with $10 \%$ phosphate buffered neutral formalin. Following dehydration in graded (75-100\%) alcohol, the tissues were embedded in paraffin. Thin tissue sections, having 5 $\mu \mathrm{M}$ thickness, were cut and stained with routine hematoxylin and eosin stain for photomicroscopic assessment. 


\section{Genotoxic and Antigenotoxic Effects}

The alkaline comet assay was performed according to the method of Singh et al. [28] with minor modifications. After 3 days of administration of CP, animals were killed and blood, liver and kidney were isolated. Cellular suspension obtained from each organ were included in an agarose gel and subjected to lysis followed by electrophoresis. The total score of DNA damage was calculated by the following equation [29].

Total DNA Damage TDD $=\%$ of cells in class $0 \times 0+\%$ of cells in class $1 \times 1+\%$ of cells in class $2 \times 2+\%$ of cells in class $3 \times 3+\%$ of cells in class $4 \times 4$

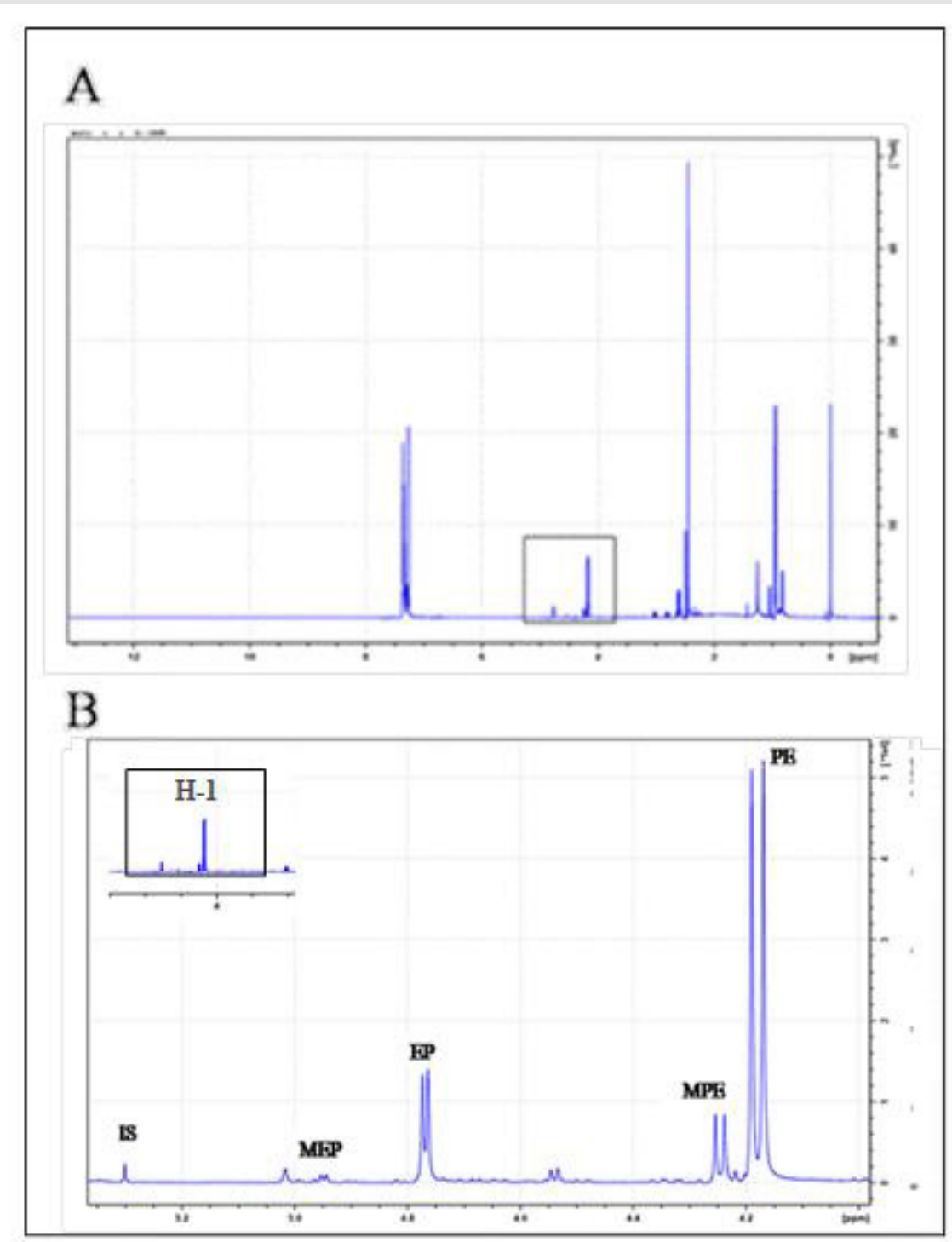

Figure 1: ${ }^{1} \mathrm{H}$ NMR spectroscopy of mixture of four ephedrine alkaloids in $\mathrm{CDCl}_{3}(400 \mathrm{MHz})$.

A. Range of $\delta$ 0-12 ppm.

B. Expansion in the range of $\delta 4-6 \mathrm{ppm}$. Labels indicate the resonance signal of the H-1 proton of each compound, MEP: methylephedrine, EP: ephedrine, MPE: methylpseudoephedrine, PE: pseudoephedrine.

\section{Results}

Figure $1 \mathrm{~A}$ shows four regions in the ${ }^{1} \mathrm{H}$ NMR spectrum of AE: The C-methyl region ( $\delta$ 0.6-1 ppm), N-methyl region $(\delta 2-2.4$ ppm), $\mathrm{H}-1$ ( $\delta$ 4-5 ppm) and the aromatic region $(\delta>7 \mathrm{ppm})$. The characteristic H-1 region, i.e. the signals of the benzylic protons, was used to differentiate between the ephedrine analogues as their $\mathrm{H}-1$ signals are well-resolved and do not overlap with other signals in the $1 \mathrm{H}$ NMR from the extract. Four ephedrine alkaloids were detected: ephedrine at $\delta 4.77 \mathrm{ppm}(\mathrm{d}, \mathrm{J}=3.8 \mathrm{~Hz})$, pseudoephedrine at $\delta 4.18 \mathrm{ppm}(\mathrm{d}, \mathrm{J}=8.2 \mathrm{~Hz})$, methylephedrine at $\delta 4.95 \mathrm{ppm}(\mathrm{d}, \mathrm{J}=$ $3.7 \mathrm{~Hz})$ and methylpseudoephedrine at $\delta 4.25 \mathrm{ppm}(\mathrm{d}, \mathrm{J}=6.6 \mathrm{~Hz})$ as shown in (Figure 1B).

\section{${ }^{1} \mathrm{H}$ NMR Analysis}




\section{Quantification of Ephedrine Alkaloids}

According to a literature survey of Ephedra species, it was found that not all species contain ephedrine alkaloids. If they do, the major compound is usually ephedrine representing between 40 to $90 \%$ of the total alkaloid fraction. In our study, the results presented by (Figure 2) show that Ephedra alata contains a lower relative amount of ephedrine (17\%) than pseudoephedrine (69\%). Furthermore, the Ephedra plant material investigated in this study is richer in alkaloids (1.34\%) than Ephedra alata grown in Iraq $(0.2 \%)[30]$.

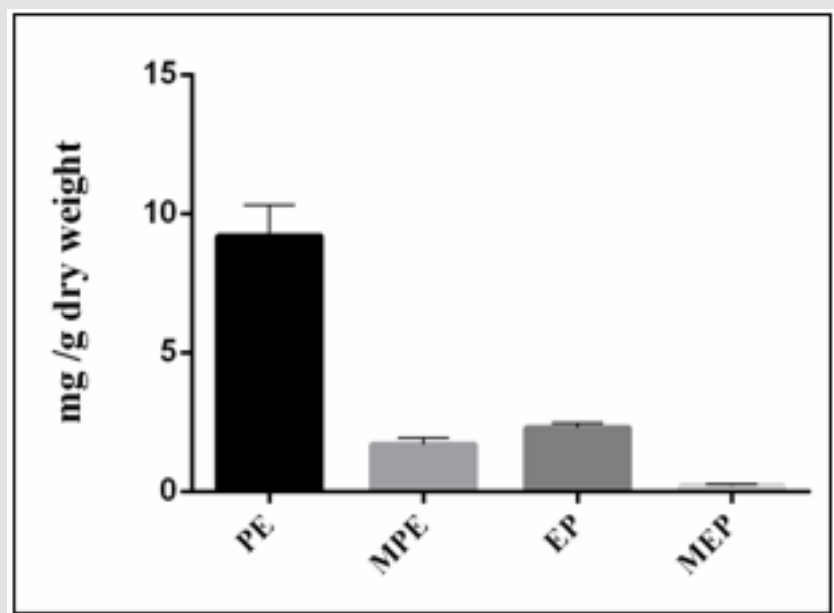

Figure 2: Content of ephedrine alkaloids (mg/g dry weight) of Ephedra alata.

PE: pseudoephedrine, MPE: Methylpseudoephedrine MEP: Methylephedrine, EP: Ephedrine.

\section{2,2-Diphenyl-1-Picrylhydrazyl Assay}

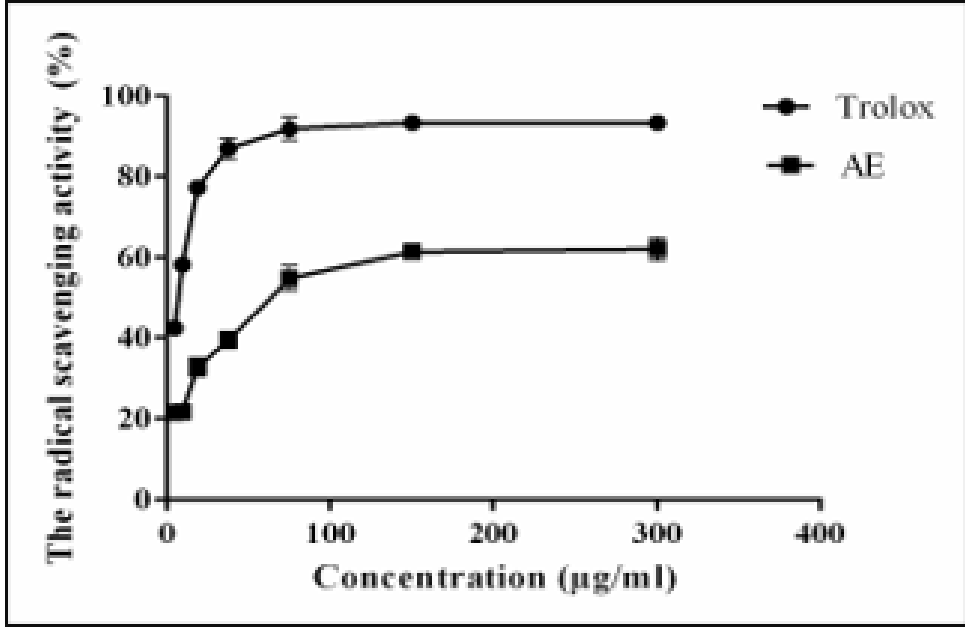

Figure 3: Radical scavenging activity of AE by DPPH method.

The radical-scavenging potential of $\mathrm{AE}$ was shown in Figure 3. The results revealed that a concentration of $64 \mu \mathrm{g} / \mathrm{ml}$ of $\mathrm{AE}$ was able to quench $50 \%$ of the DPPH free radicals.

\section{Acute Toxicity}

The acute toxicity of $\mathrm{AE}$ to the mice was assessed by determination of the seven-day LD50 value. The calculated LD50 was $500 \mathrm{mg} / \mathrm{kg}$ Table 1.
Table 1: Number of mortalities after seven days of AE treatment.

\begin{tabular}{|c|c|c|}
\hline Dose (mg/kg) & Animals (n) & Mortality(n) \\
\hline 150 & 6 & 0 \\
\hline 250 & 6 & 0 \\
\hline 350 & 6 & 1 \\
\hline 500 & 6 & 2 \\
\hline 800 & 6 & 4 \\
\hline
\end{tabular}




\section{Change in Body Weight and Organ Coefficient}

The body weight and the relative spleen weights are illustrated in (Figure 4). During the experimental period, all the studied groups survived. No significant difference was observed in kidney and liver weights between different treated groups. However, a significant decrease in body growth by $10.9 \%$ associated with a significant decrease of spleen weights by $49.3 \%$ was observed in CP groups. When $\mathrm{AE}$ was administered to CP-treated animals, the adverse effects of the CP upon these parameters were reversed.

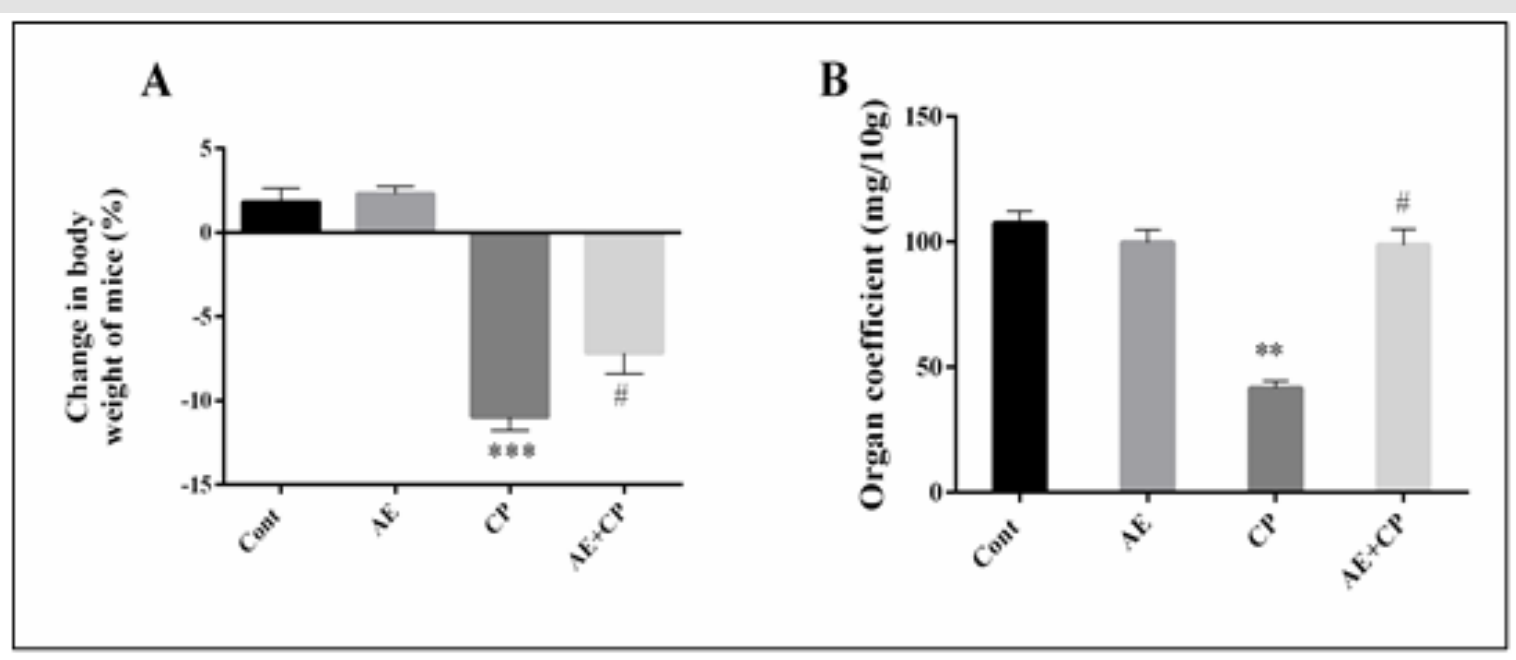

Figure 4: A: Body weight variation of mice during treatment,

B: Organ coefficient of spleen after treatment. Results are mean \pm SD $(n=6)$. The statistical significance of results was evaluated via one-way ANOVA followed by the Tukey-multiple comparison test. ${ }^{* * *} \mathrm{P}<0.001$ means significant difference between treated animals and control group (Cont). ${ }^{* *} \mathrm{P}<0.01$ means significant difference between treated animals and control group (Cont). \# $\mathrm{P}<0.05$ means significant difference between animals treated with $\mathrm{CP}$ and $\mathrm{AE}+\mathrm{CP}$-treated groups.

\section{Serum Biochemistry Results}

As shown in (Figure 5), the serum AST, ALT and CR levels were significantly increased $(\mathrm{p}<0.001)$ following administration of $\mathrm{CP}$ as compared to control group. However, combined treatment AE+CP showed normalization in these serum biochemical parameters.

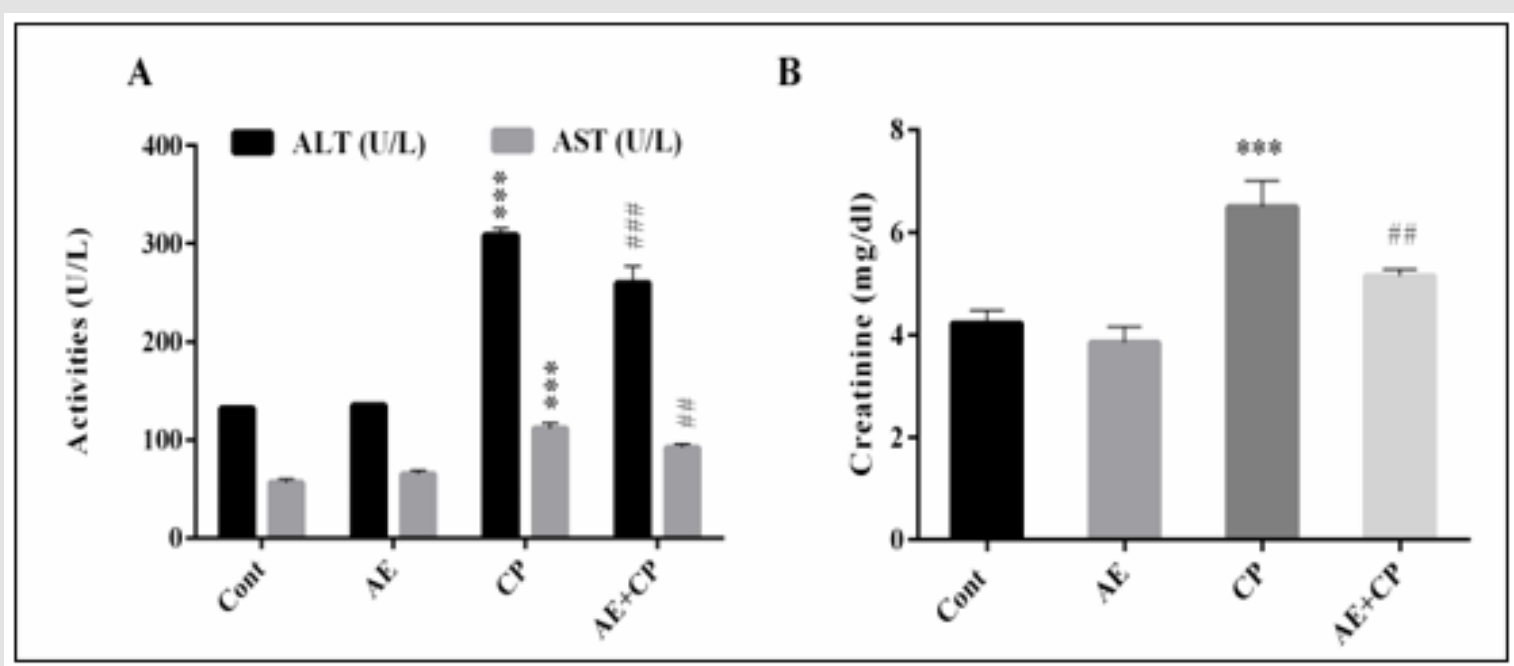

Figure 5: Transaminase activities (A) and Creatinine (CR) level in serum mice after treatment (B). Results are mean \pm SD ( $\mathrm{n}=$ 6). The statistical significance of results was evaluated via two-way ANOVA followed by the Tukey-multiple comparison test. *** $\mathrm{p}<0.001$, means significant difference between treated animals and control group (Cont). \#\# $\mathrm{p}<0.01$, means significant difference between animals treated with $\mathrm{CP}$ and $\mathrm{AE}+\mathrm{CP}$-treated groups. \#\#\# $\mathrm{p}<0.001$, means significant difference between animals treated with $\mathrm{CP}$ and $\mathrm{AE}+\mathrm{CP}$-treated groups. 


\section{Oxidative Stress}

Oxidative stress markers, superoxide dismutase (SOD), catalase (CAT) and malondialdehyde (MDA) are shown in Figure 6. Administration of CP $(p<0.001)$ decreased the level of SOD and
CAT associated with significant increase in MDA levels in liver and kidney tissue. Treatment of mice with $\mathrm{AE}+\mathrm{CP}$ significantly increased the kidney and liver level of SOD and CAT. Furthermore, AE significantly reduced the lipid peroxidation.

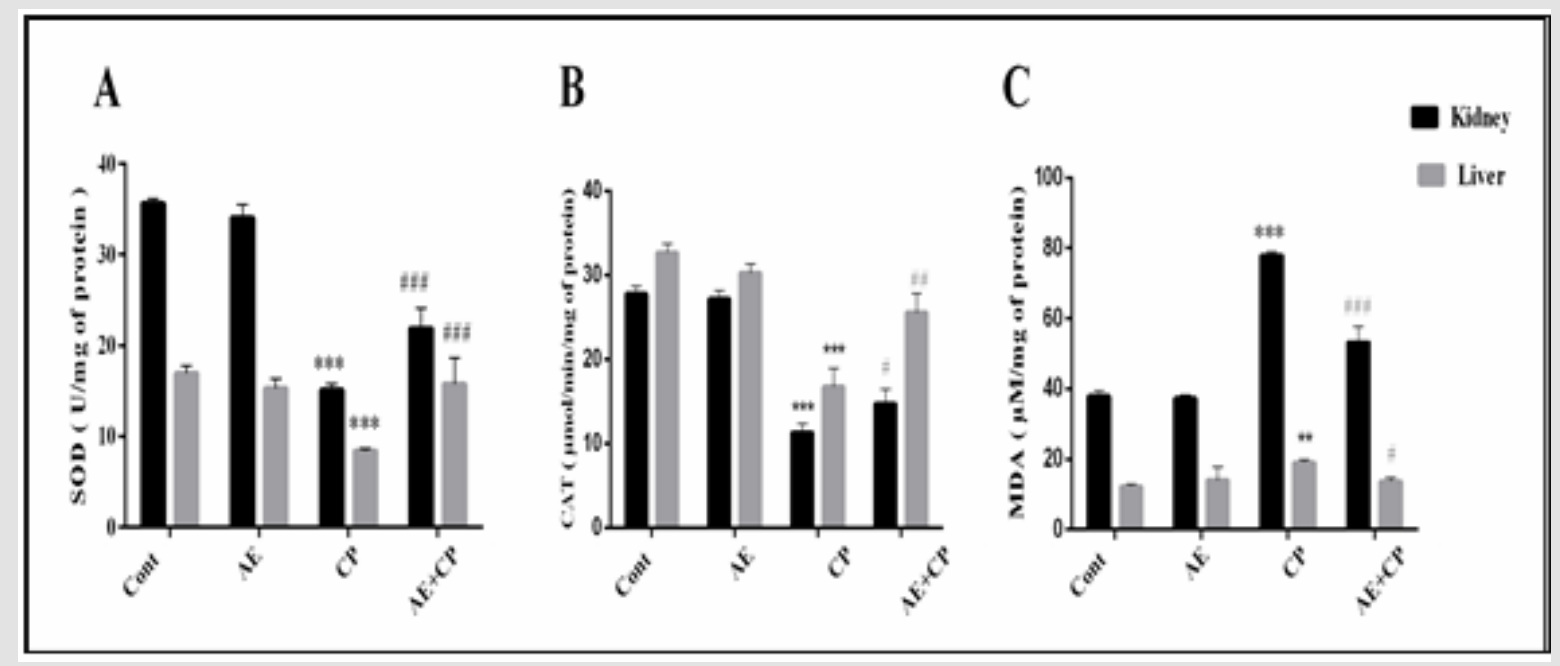

Figure 6: A: Superoxide dismutase (SOD) levels, B: Catalase (CAT) levels, C: Malondialdehyde (MDA) levels in kidney and liver cells of all experimental groups. Results are mean \pm SD $(n=6)$. The statistical significance of results was evaluated by two-way ANOVA followed by the Tukey-multiple comparison test. ${ }^{* * *} p<0.001$, means significant difference between treated animals and control group (Cont). ${ }^{* *} \mathrm{p}<0.01$, means significant difference between treated animals and control group (Cont). \#\#\# $\mathrm{p}<0.001$, means significant difference between animals treated with CP and AE+CP-treated groups. \#\# $\mathrm{p}<0.01$, means significant difference between animals treated with $\mathrm{CP}$ and $\mathrm{AE}+\mathrm{CP}$-treated groups. $\# \mathrm{p}<0.05$, means significant difference between animals treated with $\mathrm{CP}$ and $\mathrm{AE}+\mathrm{CP}$-treated groups.

\section{Histopathology}

The effect on the histology of the kidney of the experimental groups of mice was shown in (Figure $7 \mathrm{a}-\mathrm{f}$ ). Histopathological findings of control (Figure 7A) and E.A group (Figure 7B) showed normal glomerulus and tubules with regular morphology. A single injection of cisplatin caused a significant pathological change in the mice kidney characterized by glomerular (GN) and tubular necrosis (TN), tubular dilatation, and tubular cast formation (Figure 7C).
Methanolic extract of Ephedra alata significantly reversed these changes and showed a marked protection against cisplatin-induced kidney damage (Figure 7D). In the liver, administration of EA (Figure 7B) did not produced any significant change in the cellular architecture, whereas $20 \mathrm{mg} / \mathrm{kg}$ of cisplatin caused hepatic necrosis and inflammatory aggregate (Figure 7C). Histological sections of mice co-treated with EA showed similar cell architecture to sections of untreated mice (Figure 7D). 


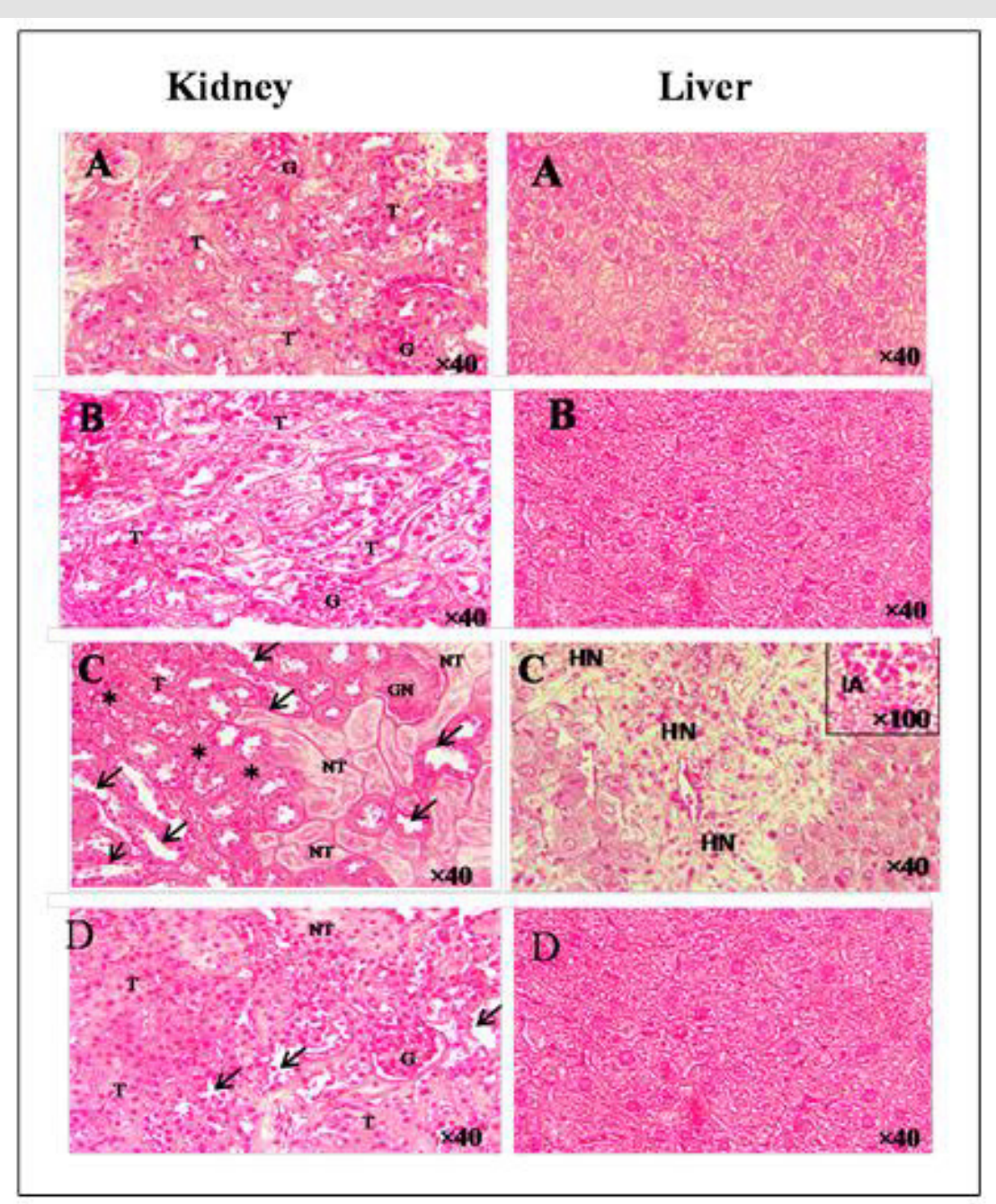

Figure 7: Hematoxylin and eosin staining of kidney and liver.
A. Control group,
B. AE group,
C. CP group,

$\mathrm{EP}+\mathrm{CP}$ group. (G) glomerulus, (T) tubules, (GN) glomerular necrosis, (arrow) tubular dilatation, (stars) tubular cast formation, $(\mathrm{HN})$ hepatocyt necrosis, (IA) inflammatory aggregate.

\section{Genotoxic Effects}

The administration of $\mathrm{AE}$ did not show genotoxic effects in kidney, liver or blood cells. On the other hand, CP produced a strong genotoxic effect $(p<0.001)$ in all of the observed types of cells of balb c mice (Figure 8) The co-treatment of AE+CP caused a statistically significant lower genotoxic effect than CP alone ( $p<$ 0.001). However, AE protects just liver $(\mathrm{p}<0.01)$ and blood $(\mathrm{p}<$ 0.05 ) against DNA damage induced by $\mathrm{CP}$. These results proved an antigenotoxic effect of AE of Ephedra alata. 


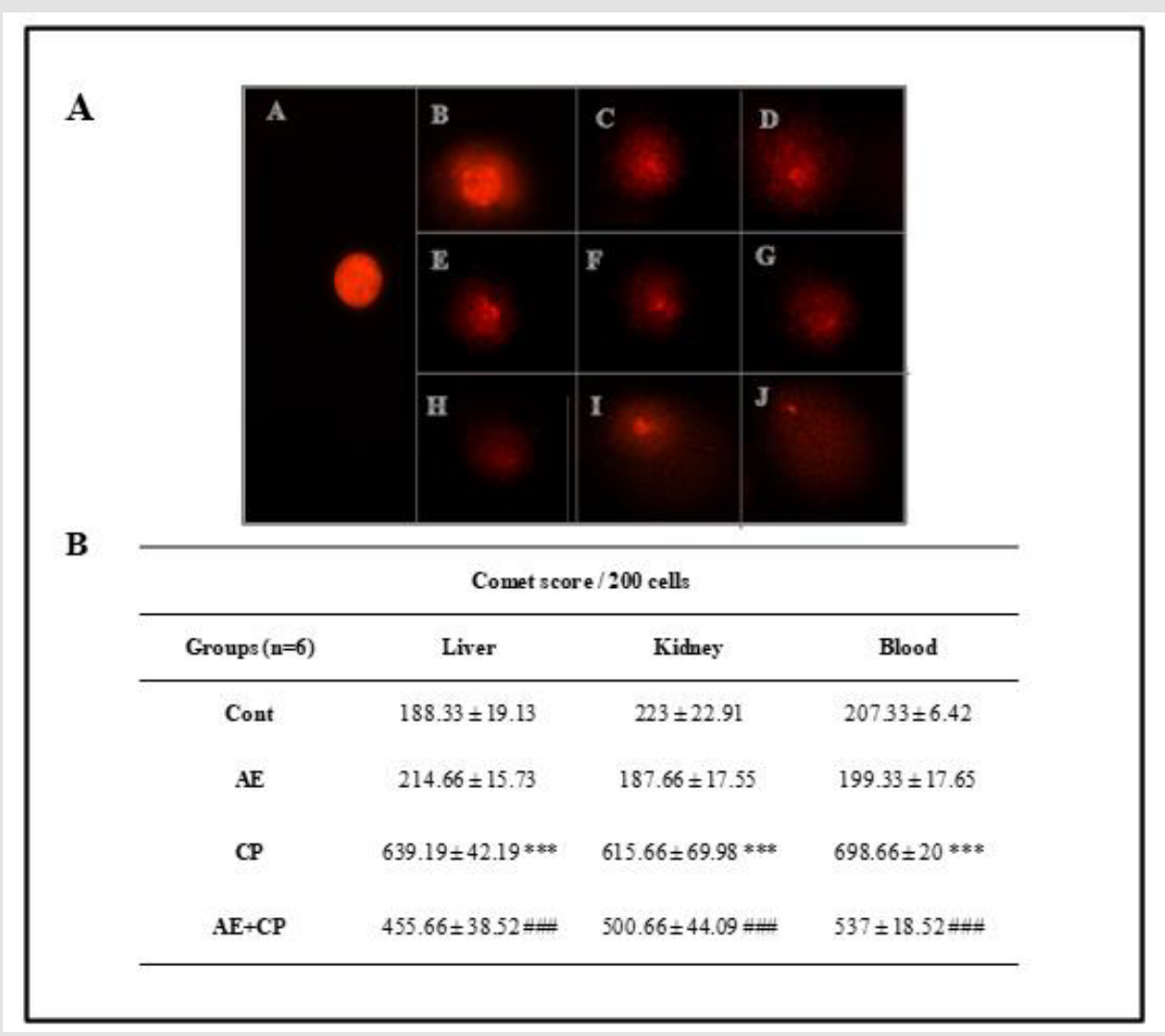

Figure 8: A. Profile of different comet classes of mice treated with cisplatin. (A) Class 0; (B) Class 1; (C, D, E) Class 2; (F, G, H) Class 3; (I, J) Class 4. B. In vivo comet score of liver, kidney and blood cells. Results are mean \pm SD $(n=6)$. The statistical significance of results was evaluated via two-way ANOVA followed by multiple comparisons. ${ }^{* *} p<0.001$, means significant difference between treated animals and control group (Cont). \#\#\# p $<0.001$, means significant difference between animals treated with $\mathrm{CP}$ and $\mathrm{AE}+\mathrm{CP}$-treated groups.

\section{Discussion}

$\mathrm{CP}$ is a commonly used chemotherapeutic agent against numerous solid tumors [31]. During the normal clinical treatment, excessive formation of ROS and lipid peroxidation play an important role in cisplatin-induced nephrotoxicity [32]. ROS are continuously formed in vivo in healthy subjects under physiological conditions. Various enzymes and non-enzymatic compounds in the cell prevent ROS production and scavenge formed radicals to maintain a balance between ROS and the antioxidant defense system. When the amount of ROS exceeds the capacity of the cell or organ antioxidant defense system, the normal function is disrupted and tissue damage develops [33]. A number of antioxidants have been reported to reduce oxidative stress and prevent cisplatin nephrotoxicity [34]. Scientific research focused on new molecules and natural substances to be included in the diet of patients for reducing the toxicity of chemotherapy. In this line, vegetables are rich source of nutraceutical compounds, hence known as protective foods. Several studies have proved that the use of different antiinflammatory agents is effective against cisplatin deleterious effects on kidney and liver.
So far, researchers have found that alkaloids extracted from many plants, such as aaptamine [35], piperine [36], berberine [37], and pseudoephedrine/ephedrine [38] could protect against hepatorenal toxicity. Ephedrine/pseudoephedrine have a chemical structure similar to epinephrine (adrenaline) and have the capacity to mimic partially the effects of endogenous adrenaline to the body. Studies of clinical trials show that cisplatin/epinephrine injection reduced tumor size in patients with different types of cancer. Furthermore, no adverse events such as nephrotoxicity, neurotoxicity or ototoxicity have been reported with use of this preparation [39]. The present study was performed to test the capacity of Ephedra alkaloids, known for their anti-inflammatory potential, would ameliorate the damage caused by $\mathrm{CP}$ such as oxidative stress, inflammation and genotoxicity caused by CP clinical treatment. The findings from the present study indicate that groups treated with CP showed a significant reduction in the body weight that could be attributed to a decrease in the food consumption or to the effects of this toxic drug on the gastrointestinal tract [40]. On the other hand, the reduction of spleen weight could be explained by inflammation and oxidative stress inducing apoptosis of spleen 
cells by extrinsic pathway [6]. Treatment with AE alone did not cause any significant change in spleen or body weight. Compared to $\mathrm{CP}$ group, combined treatment resulted in a significant increase $(\mathrm{P}$ $<0.05$ ) in body and spleen weight.

A number of studies have demonstrated the hepatorenal toxicity of cisplatin [41-43]. ALT and AST are the most common indicators for the diagnosis of liver cell damage while the deleterious effect of cisplatin on kidney function may be revealed by the alteration in kidney biomarker enzymes including CR. In our study, a single administration of a high-dose CP $(20 \mathrm{mg} / \mathrm{kg})$ over a 72 -h period caused a significant increase ( $<<0.001)$ of AST, ALT and CR. This is a secondary event from cisplatin-induced liver and kidney damage which leads to changes in their membrane permeability, resulting in the release of enzymes from cells. Daily admission of AE decreased the serum level of aminotransferase and creatinine in the $\mathrm{AE}+\mathrm{CP}$ group. This protective effect of pseudoephedrine/ephedrine against hepatotoxicity has been demonstrated also by Wu et al. [44]. One of the fundamental mechanisms of cellular damage involves reaction of free radicals with lipids causing peroxidation which eventually results in the release of products such as malondialdehyde. In the present study, CP treatment increased lipid peroxidation and significantly impaired antioxidant enzymes SOD and CAT in kidney and liver cells. Co-treatment with AE reduced the decrease in liver and kidney activities of SOD and CAT and the increase of lipid peroxidation induced by cisplatin, suggesting that SOD and CAT may participate in the protection of $\mathrm{AE}$ against cisplatin-induced oxidative stress injury.

The main disadvantages of chemotherapeutic agents are their relatively non-selective damage of normal tissues as well as tumor cells [45]. Comet assay results revealed that the treatment with $\mathrm{CP}$ induced DNA damage in liver, kidney and blood cells. However, AE alone did not induce any genotoxic effect. Absence of genotoxic effects of ephedrine observed in the present study is in accordance with results of several studies on ephedrine genotoxicity in various test systems. Thus, ephedrine did not exhibit genotoxic effects in human lymphocytes comet test [46], Salmonella mutagenicity tests [47], and chromosome aberrations in vitro [48]. The observed decrease of DNA damage after co-treatment with AE demonstrated the antigenotoxic effect of alkaloids of Ephedra alata. It has been postulated that exposure to AE can result in increased ROS formation, which may induce oxidative stress in tissues. However, whether ephedrine/pseudoephedrine is an oxidant, or an antioxidant agent is a controversial issue. In some studies, EP/PE has been shown to induce oxidative injury [49], while others have reported that it protects against liver failure and lipoperoxidation [50]. Some beneficial effects of $\mathrm{AE}$, such as vasoconstriction, inhibition of lipid peroxidation or anti-inflammatory effect could be responsible to this protective effect.

\section{Conclusion}

$\mathrm{AE}$, containing pseudoephedrine/ephedrine, protects against liver injury induced by cisplatin via inhibition of liver and kidney oxidative stress injury in mice. Further research is in progress in our laboratory to explore the protective effect of $\mathrm{AE}$ on antitumor activity of cisplatin.

\section{Ethics Approval}

All animal experiments were performed in accordance with the guidelines for the care and use of laboratory animals published by the US National Institutes of Health. The study protocols. was approved by the Ethics Committee of the University Hospital Fattouma-Bourguiba of Monastir, Tunisia. Consent for publication: not applicable.

\section{Availability of Data and Material}

Address to the authors for the uses of the images and data included in the manuscript.

\section{Competing Interests}

The authors declare that they have no competing interests.

\section{Acknowledgments}

The authors acknowledge the "Ministry of Higher Education, Scientific Research and Technology, Tunisia," for the support of this study.

\section{Funding}

This work not supported by any funding agencies.

\section{References}

1. Wang D, Lippard SJ (2005) Cellular processing of platinum anticancer drugs. Nature reviews Drug discovery 4: 307-320.

2. Mortelmans K, Zeiger E (2000) The Ames Salmonella/microsome mutagenicity assay. Mutation Research/Fundamental and Molecular Mechanisms of Mutagenesis 455(1-2): 29-60.

3. Kim HK, Choi YH, Chang W-T, Verpoorte R (2003) Quantitative analysis of ephedrine analogues from Ephedra species using ${ }^{1} \mathrm{H}-\mathrm{NMR}$. Chemical and pharmaceutical bulletin 51(12): 1382-1385.

4. Abourashed EA, El-Alfy AT, Khan IA, Walker L (2003) Ephedra in perspective--a current review. Phytotherapy research: PTR 17(7): 703712.

5. Afsar T, Razak S, Almajwal A, Khan MR (2018) Acacia hydaspica R. Parker ameliorates cisplatin induced oxidative stress, DNA damage and morphological alterations in rat pulmonary tissue. BMC complementary and alternative medicine 18(1): 49.

6. Ani HA, Kadi KA, Al Obaidi ED, Shalan N, Rawi NA, et al. (2014) Investigation of the Alkaloids of Two Ephedra Spp. Wildly Grown in Iraq. Jordan Journal of Pharmaceutical Sciences 7(3). 191-198.

7. Appenroth D, Fröb S, Kersten L, Splinter F-K, Winnefeld K (1997) Protective effects of vitamin $\mathrm{E}$ and $\mathrm{C}$ on cisplatin nephrotoxicity in developing rats. Archives of toxicology 71(11): 677-683. 
8. Astolfi L, Ghiselli S, Guaran V, Chicca M, Simoni E, et al. (2013) Correlation of adverse effects of cisplatin administration in patients affected by solid tumours: a retrospective evaluation. Oncology reports 29(4): 12851292.

9. Banerjee S, Sinha K, Chowdhury S, Sil PC (2018) Unfolding the mechanism of cisplatin induced pathophysiology in spleen and its amelioration by carnosine. Chemico-biological interactions 279: 159-170.

10. Bradford MM (1976) A rapid and sensitive method for the quantitation of microgram quantities of protein utilizing the principle of protein-dye binding. Analytical biochemistry 72: 248-254.

11. Burris III AH, Vogel CL, Castro D, Mishra L, Schwarz M, et al. (1998) Intratumoral cisplatin/epinephrine-injectable gel as a palliative treatment for accessible solid tumors: a multicenter pilot study. Otolaryngology-Head and Neck Surgery 118(4): 496-503.

12. Cagin YF, Atayan Y, Sahin N, Parlakpinar H, Polat A, et al. (2016) Beneficial effects of dexpanthenol on mesenteric ischemia and reperfusion injury in experimental rat model. Free radical research 50(3):354-365.

13. Camera E, Mastrofrancesco A, Fabbri C, Daubrawa F, Picardo M, et al. (2009) Astaxanthin, canthaxanthin and beta-carotene differently affect UVA-induced oxidative damage and expression of oxidative stressresponsive enzymes. Experimental dermatology 18(3): 222-231.

14. Çetin R, Devrim E, Kılıçoğlu B, Avcı A, Çandır Ö, et al. (2006) Cisplatin impairs antioxidant system and causes oxidation in rat kidney tissues: possible protective roles of natural antioxidant foods. Journal of Applied Toxicology 26(1): 42-46.

15. Chen K, Schmidt CF (1924) The action of ephedrine, the active principle of the Chinese drug Ma Huang. Journal of Pharmacology and Experimental Therapeutics 24(5): 339-357.

16. Choi B-M, Kim S-M, Park T-K, Li G, Hong S-J, et al. (2007) Piperine protects cisplatin-induced apoptosis via heme oxygenase-1 induction in auditory cells. The Journal of nutritional biochemistry 18(9): 615-622.

17. Claiborne A (1986) Catalase activity. CRC handbook of methods for oxygen radical research.

18. Collins AR, Dobson VL, Dusinska M, Kennedy G, Stetina R, et al. (1997) The comet assay: what can it really tell us? Mutation research $375(2)$ : 183-193.

19. Conklin KA (2000) Dietary antioxidants during cancer chemotherapy: impact on chemotherapeutic effectiveness and development of side effects. Nutrition and cancer 37(1): 1-18

20. Cui JF, Zhou TH, Zhang JS, Lou ZC (1991) Analysis of alkaloids in Chinese Ephedra species by gas chromatographic methods. Phytochemical analysis 2(3): 116-119.

21. De Oliveira Mora L, Antunes LMG, Francescato HsDC, Bianchi MdLP (2003) The effects of oral glutamine on cisplatin-induced nephrotoxicity in rats. Pharmacological Research 47(6): 517-522

22. Funk F, Krüger K, Henninger C, Wätjen W, Proksch P, et al. (2014) Spongean alkaloids protect rat kidney cells against cisplatin-induced cytotoxicity. Anti-cancer drugs 25(8): 917-929.

23. Ghasemi M, Azarnia M, Jamali M, Mirabolghasemi G, Nazarian S, et al. (2014) Protective effects of Ephedra pachyclada extract on mouse models of carbon tetrachloride-induced chronic and acute liver failure. Tissue and Cell 46(1): 78-85.

24. Gheorghiev MD, Hosseini F, Moran J, Cooper CE (2018) Effects of pseudoephedrine on parameters affecting exercise performance: a meta-analysis. Sports medicine-open 4: 44.

25. Han Y, Zhu J, Wu Z (2016) Ephedra protects rats against acute liver failure induced by D-galactosamine and lipopolysaccharide. Zhonghua gan zang bing za zhi= Zhonghua ganzangbing zazhi= Chinese journal of hepatology 24(2): 127-129.
26. Hegarty M, Chisholm D (2002) Chemotherapy and anaesthesia. Current Anaesthesia and Critical Care 13(3): 168-174.

27. Hilliard CA, Armstrong MJ, Bradt CI, Hill RB, Greenwood SK, et al. (1998) Chromosome aberrations in vitro related to cytotoxicity of nonmutagenic chemicals and metabolic poisons. Environmental and molecular mutagenesis 31(4): 316-326.

28. Hosseinian S, Roshan NM, Khazaei M, Shahraki S, Mohebbati R, et al. (2018) Renoprotective effect of Nigella sativa against cisplatin-induced nephrotoxicity and oxidative stress in rat. Saudi Journal of Kidney Diseases and Transplantation 29(1): 19-29.

29. Houmani H, Rodriguez-Ruiz M, Palma JM, Abdelly C, Corpas FJ, et al. (2016) Modulation of superoxide dismutase (SOD) isozymes by organ development and high long-term salinity in the halophyte Cakile maritima. Protoplasma 253(3): 885-894.

30. Jyothilakshmi V, Thellamudhu G, Kumar A, Khurana A, Nayak D, et al. (2013) Preliminary investigation on ultra-high diluted B. vulgaris in experimental urolithiasis. Homeopathy 102(3): 172-178.

31. Karale S, Kamath JV (2017) Effect of daidzein on cisplatin-induced hematotoxicity and hepatotoxicity in experimental rats. Indian journal of pharmacology 49(1): 49-54.

32. Koyuncu I, Kocyigit A, Gonel A, Arslan E, Durgun M, et al. (2017) The Protective Effect of Naringenin-Oxime on Cisplatin-Induced Toxicity in Rats. Biochemistry research international 2017: 9478958.

33. Kuhlmann M, Burkhardt G, Köhler H (1997) Insights into potential cellular mechanisms of cisplatin nephrotoxicity and their clinical application. Nephrology, dialysis, transplantation: official publication of the European Dialysis and Transplant Association-European Renal Association 12(12): 2478-2480.

34. Kumar M, Dahiya V, Kasala ER, Bodduluru LN, Lahkar M, et al. (2017) The renoprotective activity of hesperetin in cisplatin induced nephrotoxicity in rats: Molecular and biochemical evidence. Biomedicine \& Pharmacotherapy 89: 1207-1215.

35. Lee M (2011) The history of Ephedra (ma-huang). JR Coll Physicians Edinb 41(1): 78-84.

36. Malhotra H, Plosker GL (2001) Cisplatin/epinephrine injectable gel. Drugs \& aging 18(10): 787-793

37. Nam NH, Lee CW, Hong DH, Kim HM, Bae KH, et al. (2003) Antiinvasive, antiangiogenic and antitumour activity of Ephedra sinica extract. Phytotherapy Research: An International Journal Devoted to Pharmacological and Toxicological Evaluation of Natural Product Derivatives 17(1): 70-76.

38. Nishimura Y, Hyuga S, Takiguchi S, Hyuga M, Itoh K, et al. (2016) Ephedrae herba stimulates hepatocyte growth factor-induced MET endocytosis and downregulation via early/late endocytic pathways in gefitinib-resistant human lung cancer cells. International journal of oncology 48(5): 1895-1906.

39. Palipoch S, Punsawad C (2013) Biochemical and histological study of rat liver and kidney injury induced by cisplatin. Journal of toxicologic pathology 26(3): 293-299.

40. Park CH, Lee AY, Kim JH, Seong SH, Jang GY, et al. (2018) Protective Effect of Safflower Seed on Cisplatin-Induced Renal Damage in Mice via Oxidative Stress and Apoptosis-Mediated Pathways. The American journal of Chinese medicine 46(1): 157-174

41. Potocnjak I, Broznic D, Kindl M, Kropek M, Vladimir-Knezevic S, et al. (2017) Stevia and stevioside protect against cisplatin nephrotoxicity through inhibition of ERK1/2, STAT3, and $\mathrm{NF}_{-} \mathrm{B}$ activation. Food Chem Toxicol. 107(Pt A): 215-225.

42. Radaković M, Đelić N, Stanimirović Z, Plećaš-Solarović B, SpremoPotparević B, et al. (2011) Evaluation of the effects of ephedrine on human lymphocytes in the comet assay. Acta veterinaria 61(4): 363-371. 
43. Satoh M, Kashihara N, Fujimoto S, Horike H, Tokura T, et al. (2003) A novel free radical scavenger, edarabone, protects against cisplatin-induced acute renal damage in vitro and in vivo. Journal of Pharmacology and Experimental Therapeutics 305(3): 1183-1190.

44. Sharma S, Modi A, Narayan G, Hemalatha S (2018) Protective effect of Exacum lawii on cisplatin-induced oxidative renal damage in rats. Pharmacognosy magazine 13(Suppl 4): S807-S816.

45. Siddik ZH (2003) Cisplatin: mode of cytotoxic action and molecular basis of resistance. Oncogene 22(47): 7265-7279.

46. Singh NP, McCoy MT, Tice RR, Schneider EL (1988) A simple technique for quantitation of low levels of DNA damage in individual cells. Experimental cell research 175(1): 184-191.

47. Villano D, Fernandez-Pachon MS, Moya ML, Troncoso AM, Garcia-Parrilla MC, et al. (2007) Radical scavenging ability of polyphenolic compounds towards DPPH free radical. Talanta 71(1): 230-235.

\section{ISSN: 2574-1241}

DOI: 10.26717/BJSTR.2021.36.005861

Fairouz Sioud. Biomed J Sci \& Tech Res

(c) (P) This work is licensed under Creative

Submission Link: https://biomedres.us/submit-manuscript.php
48. Wang J, ShY Y (2011) Effects of ephedrine on histological structure, activities of superoxide dismutase, catalase, and content of maleic dialdehyde in kidney of finial mice. Chinese Journal of Zoology 46: 118125 .

49. Wu Z, Kong X, Zhang T, Ye J, Fang Z, et al. (2014) Pseudoephedrine/ ephedrine shows potent anti-inflammatory activity against TNF$\alpha$-mediated acute liver failure induced by lipopolysaccharide/dgalactosamine. European journal of pharmacology 724: 112-121.

50. Zhang B-M, Zhi-Bin W, Ping X, Qiu-Hong W, He B, et al. (2018) Phytochemistry and pharmacology of genus Ephedra. Chinese journal of natural medicines 16(11): 811-828.

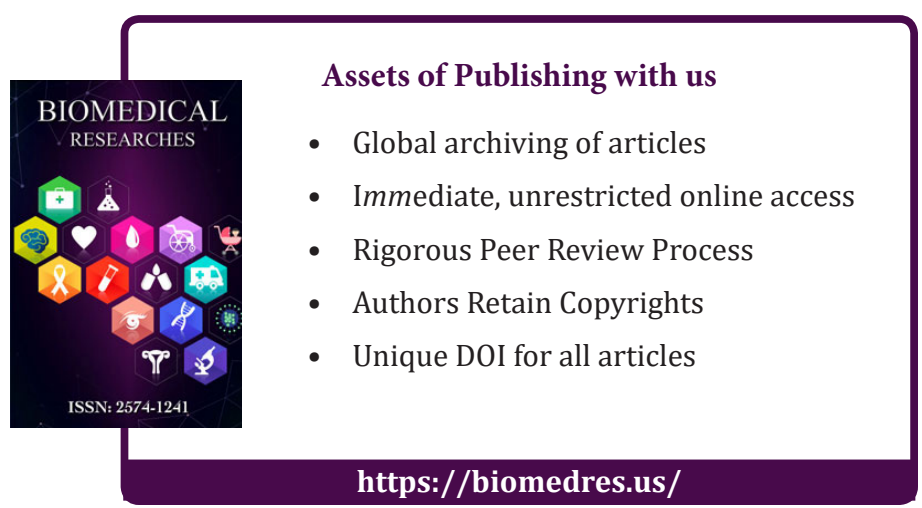

